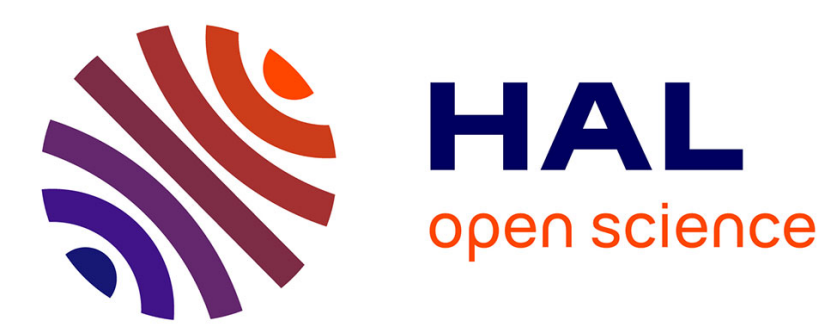

\title{
Effective seismic wave velocities and attenuation in partially molten rocks
}

Vladimir Lyakhovsky, Eyal Shalev, Ittai Kurzon, Wenlu Zhu, Laurent Montesi, Nikolai M Shapiro

\section{- To cite this version:}

Vladimir Lyakhovsky, Eyal Shalev, Ittai Kurzon, Wenlu Zhu, Laurent Montesi, et al.. Effective seismic wave velocities and attenuation in partially molten rocks. Earth and Planetary Science Letters, In press, 10.1016/j.epsl.2021.117117 . hal-03292087

\section{HAL Id: hal-03292087 \\ https://hal.science/hal-03292087}

Submitted on 20 Jul 2021

HAL is a multi-disciplinary open access archive for the deposit and dissemination of scientific research documents, whether they are published or not. The documents may come from teaching and research institutions in France or abroad, or from public or private research centers.
L'archive ouverte pluridisciplinaire HAL, est destinée au dépôt et à la diffusion de documents scientifiques de niveau recherche, publiés ou non, émanant des établissements d'enseignement et de recherche français ou étrangers, des laboratoires publics ou privés. 

Nikolai M. Shapiro ${ }^{3,4}$

91. Geological Survey of Israel, Jerusalem, Israel.

102. Department of Geology, University of Maryland, College Park, Maryland, USA

113. Institut de Sciences de la Terre, Université Grenoble Alpes, CNRS (UMR5275), CS 40700, 1238058 Grenoble Cedex 9, France.

134. Schmidt Institute of Physics of the Earth, Russian Academy of Sciences, Bolshaya 14 Gruzinskaya str., 10-1, 123242 Moscow, Russia

*) Corresponding author: vladimir.lyakhovsky@gmail.com

26 Key words: partial melt, phase transition, wave velocity, attenuation 


\section{Abstract}

Significant reduction in mechanical properties, i.e., elastic moduli and seismic wave velocities, as well as enhanced inelastic attenuation is often associated with areas of partially molten rocks. In this paper we suggest a new mechanism responsible for significant reduction of wave velocity and enhanced attenuation. The suggested mechanism considers solid-melt phase transition at thermodynamic equilibrium. Any pressure change, that takes the system out of thermodynamic equilibrium, causes solidification or melting which modifies the heat balance according to the Clausius-Clapeyron equation. The latent heat (sink or source) is transferred away or towards the interface by conductive-advective mechanism heating or cooling the entire rock mass leading to energy loss and dissipation of the mechanical energy and to seismic wave attenuation. We use simplified geometry and derive analytical solutions for wave velocity reduction and attenuation associated with a moving solid-melt interface (Stefan problem). We demonstrate that the latent heat generation due to wave-induced pressure oscillations around thermodynamic equilibrium is an efficient mechanism for energy dissipation and leads to significant reduction in mechanical properties (seismic velocities and attenuation). The highest attenuation occurs when the period of oscillation is close to the heat transfer time scale associated with the size of melt inclusions. The predicted values are approximately in agreement with large scale seismological observations, showing that seismic waves are mostly attenuated within the shallow parts of Earth's crust and mantle, and are associated with possible presence of melt.

\section{Introduction}

Melt fraction is largely present in the crust and uppermost mantle of the Earth. The partially molten rocks are characterized by enhanced mobility because of their elevated buoyancy and reduced viscosity and, therefore, play a key role in many geodynamical processes. Partial melting of silicate rocks occur in regions within the crust and in the uppermost mantle where the solidusliquidus transition can be reached by different mechanisms such as: decompression (e.g.,Niu, 1997), heating by uprising hot material such as mantle plumes (e.g., Campbell, 2005), compositional changes such as the addition of water (e.g., Asimow and Langmuir, 2003), or by mechanical processes such as frictional melting (e.g., (Di Toro et al., 2006). The most direct manifestations of the presence of the molten rocks are the volcanic deposits observed at the surface, and the magmatism imprinted in geological records. Initial magmas form at depths and driven by 
60 buoyancy, rise toward the surface, through the uppermost mantle and the crust. While volcanic 61 deposits of molten rock reach the surface, most of the magmas and molten rock remain stored at 62 depth. Understanding how the magma and molten rocks are stored at depth is one of the major 63 challenges in volcanology and igneous geology. Traditional views, implying the existence of 64 concentrated "high-melt" volumes, forming well identified intrusions or magma chambers, is 65 challenged today with new concepts suggesting a more distributed storage of melts in a form of 66 low melt-fraction "mush reservoirs" (Jackson et al., 2018). The form of such storage at depth 67 strongly affects the evolution of magmas/melts and their mobility, changing the hydraulic connectivity of volcano-magmatic systems (Pinel et al., 2010). Melt distribution within the shallow

69 layers of the crust is of great importance for estimating the potential volcanic activity. Estimation 70 of the volume of erupted volcanic products from geological records shows that past rates of 71 volcanism were very variable both for individual volcanic systems and for the whole Earth. In 72 particular, the level of volcanic activity that occurred during human history is rather weak 73 compared to some pre-human major events such as explosive super-Plinian eruptions, the 74 emergence of flood basalts and the generation of large igneous provinces (e.g., Bryan et al., 2010); 75 such strong events are often called upon to explain environmental changes and mass extinctions 76 (Sobolev et al., 2011). The possibility of occurrence of new major volcanic episodes with great 77 impact at a global scale cannot be excluded and its understanding requires the estimation of melt 78 distribution within the shallow layers of the crust.

The presence of melt is also of major importance for global mantle dynamics and plate 80 tectonics. Mantle convection in the vicinity of the major convergent and divergent plate boundaries 81 is strongly influenced by the melt fraction, present in the subduction zone mantle wedges (e.g., 82 Gerya and Meilick, 2011) and beneath the mid-oceanic ridges (e.g., Niu, 1997). The partial melt 83 is also suggested to contribute significantly to the mechanical weakness of the asthenosphere (e.g., 84 Chantel et al., 2016) and to facilitate the widespread small- scale sub-lithospheric convection(e.g., 85 van Hunen et al., 2005). Partial melt might be present in the continental crust driving fast 86 deformation of the rocks, and affecting the orogenesis (Chen et al., 2018). Also, partial melt can 87 lubricate seismogenic faults (Di Toro et al., 2006) and, therefore, affect earthquake dynamic and 88 seismo-tectonic cycles.

89 Understanding many ongoing key geodynamic processes and related natural hazards 90 requires information on the distribution of partial melt storage systems and reservoirs in the Earth's 
91 crust and upper mantle. This information can be obtained only by methods of deep geophysical

92 sounding, searching for the areas with abnormal physical and mechanical properties. One possible

93 approach is finding the presence of partial melt in the subsurface by searching for elevated

94 electrical conductivity (Watanabe and Kurita, 1993). So far, large scale electromagnetic and

95 magneto-telluric surveys were used to study partially molten rocks located at depths beneath mid

96 oceanic ridges (e.g., Baba et al., 2006) and volcanoes (e.g., Hill et al., 2009).

97 Another approach is to use the significant reduction in mechanical properties, i.e., elastic

98 moduli and seismic wave velocities, as well as enhanced anelastic attenuation in the areas with

99 partially molten rocks that can be measured with different seismological methods (Debayle et al.,

100 2020). This approach is much widely used because of the existence of numerous permanent and

101 temporary seismic networks. In highly active volcanic systems the mobility of melt can lead to

102 recordable seismic radiation (Chouet, 1996; Shapiro et al., 2017). However, in most cases, the

103 detection of molten rocks requires using different methods of seismic imaging. Since it is widely

104 accepted that the shear modulus and S-wave velocity are most affected by the presence of melt (or

105 more generally fluid fraction), the S-wave seismic tomography is particularly suitable to image the

106 regions with presence of significant portions of melt such as in mid-oceanic ridges (e.g., Conder

107 et al., 2002) hotspots (Allen et al., 2002). Strong negative P-wave seismic velocity anomalies can

108 also indicate the presence of melt, especially beneath volcanoes, and in many cases, the Vp/Vs

109 ratio is used to trace the melts (e.g., Koulakov et al., 2020). Melt-induced variations of the elastic

110 moduli also affect the reflectivity structure in the crust and in the uppermost mantle. Therefore,

111 the melt-enriched regions can be imaged with the reflection seismic methods or with its passive

112 seismology analog: the receiver functions (e.g., Rychert et al., 2013). Different methods of

113 attenuation measurement using amplitudes of direct waves (P, S) and the coda of seismograms can

114 be used in different geological settings (e.g., Prudencio and Manga, 2020). The separation of the

115 intrinsic attenuation and scattering is a particularly challenging issue. The latter can be strongly

116 enhanced by the presence of small pockets of partially molten rocks.

117 As mentioned above (Jackson et al., 2018), magma and melt may be stored not within large

118 intrusions or reservoirs but rather distributed over a system of small melt pockets or layers with

119 dimensions smaller than seismic wavelengths. In such cases, the preferred orientation of these

120 small partially molten volumes may result in seismic anisotropy. This mechanism can contribute

121 to the well-known radial seismic anisotropy in the upper mantle (Ekström and Dziewonski, 1998). 
122 More recently, radial seismic anisotropy has been discovered beneath some large volcanic systems

123 (e.g., Jaxybulatov et al., 2014) where it is believed to be caused by the presence of large sill

124 complexes, composed of many nearly horizontal layers of magmatic rocks with different degree 125 of partial melting.

126 Interpretation of the seismological observations requires understanding of the effects of the 127 properties of the partially molten rocks on the melt fraction and topology of melt inclusions. Zhu 128 et al. (submitted) approach this problem by numerical simulations of the effective elastic properties 129 of different samples prepared in laboratory from a powder mixture of natural basalt with wide 130 range of melt fraction values. They demonstrate that in-spite of complex topology of melt 131 distribution the simple geometrical model of the elastic media with spherical fluid inclusions 132 provides a good approximation for the mechanical behavior of the solid-fluid system. However, 133 their static modelling, similar to most of previous studies, ignores the impact of heat and mass 134 transport across the solid-melt interface associated with pressure oscillations. We utilize the simple 135 geometry of spherical melt inclusions and develop analytical solution predicting the impact of the 136 solid-melt phase transition on the bulk elasticity and wave attenuation.

137 In the next section we briefly review averaging models for effective properties of partially 138 molten rocks. Later we provide key aspects of the existing mechanical models of partially molten 139 rocks. Then we discuss the technique of sample preparation and the applied numerical method. 140 Section 5 describes results of numerical simulations and their comparison with existing models of 141 effective elasticity of partially molten rocks (see Appendix A for model details). Then we 142 summarize the main relations connecting bulk elasticity and wave attenuation with moving 143 boundary between solid and melt phases. The detailed derivations are presented in Appendix B. 144 Our findings lead to practical suggestions that may improve the interpretation of seismological 145 observations in areas with partially molten rocks.

\section{2. Effective properties of Partially Molten Rocks}

$148 \quad 2.1$ Bulk elasticity and seismic wave velocities

149 A partially molten rock is a composite material with solid and liquid (melt) fractions. 150 Effective elastic properties of composite materials have been studied for decades starting with 151 original works by Voigt (1890) and Reuss (1929) who suggested upper and lower bound values 152 for any given volume fraction of constituents, ignoring the topology of the partially molten rock 
153 (see Appendix A for detailed description of these and other models). The Voigt (1890) iso-strain 154 model assumes that all constituents have the same strain and provides the upper bound value, while 155 the Reuss (1929) iso-stress assumption leads to the lower bound value. In the case of the solid156 melt system with zero shear modulus of the liquid phase, lower bound value for the shear modulus 157 is zero. Converting elastic moduli to $V_{\mathrm{p}}$ and $V_{\mathrm{s}}$ values allows estimating their expected reduction 158 as a function of the melt fraction (Fig. 1). The expected reduction of the $V_{\mathrm{p}}$ values is relatively 159 minor, smaller than $20 \%$ velocity reduction for melt fractions of up to $25 \%$ (blue curves in Fig. 1). 160 However, the possible range of $V_{\mathrm{s}}$ values is large (red curves in Fig. 1). The iso-strain, Voigt model 161 predicts only minor reduction, whereas the iso-stress model predicts zero $V_{\mathrm{s}}$ values. This wide 162 range is not useful for practical applications and cannot be used to constrain the melt fraction. 163 More realistic bounds giving the narrowest possible range of bulk elasticity without specifying the 164 geometries of the melt inclusions is the Hashin-Shtrikman-Walpole models. Several models 165 consider sphere or ellipsoid inclusion shape and developed analytical solutions (equations a3-a5, 166 Appendix A) connecting effective elastic properties with melt fraction. Several numerical methods 167 such as self-consistent and differential effective medium methods were proposed to account for 168 inclusion interaction and wide range of possible geometries. These methods as well as more 169 accurate evaluation of the effective elastic properties achieved by characterization of the microstructure geometry are briefly discussed in the Appendix A.

\subsection{Wave attenuation}

173 Quantitative interpretation of seismic wave attenuation in partially molten rocks addresses 174 two general mechanisms. One mechanism considers viscous dissipation due to melt flow or squirt 175 flow in thin films (e.g., Mavko et al., 2009; O’Connell and Budiansky, 1977). Another mechanism 176 addresses dislocation-diffusion stress relaxation in distributed melt pockets or inclusions (e.g., 177 Karato and Spetzler, 1990; Morris and Jackson, 2009). Both approaches were examined in 178 theoretical and laboratory studies, using natural rocks and synthetic materials, quantifying the 179 seismic attenuation, and trying to establish a physical understanding of these mechanisms (Faul 180 and Jackson, 2015)(Yamauchi and Takei, 2016). Each approach has its shortcomings; while 181 viscous dissipation, due to melt flow, requires unrealistically high melt viscosity (Faul and

182 Jackson, 2015), the dislocation-diffusion mechanism does not explain the strong association of 183 attenuation with the onset of melting (Fontaine et al., 2005). 

and Budiansky, 1977). In the case when fluid fills narrow crack-like zones, the scaling relations should account for the crack aspect ratio or the ratio between opening and length $(c / a)$. They concluded that the most efficient attenuation of fluid-saturated cracked solids is expected for a frequency range defined by two bounding frequencies:

$$
\omega_{1}=\frac{K}{\eta}\left(\frac{c}{a}\right)^{3} \text { and } \omega_{2}=\frac{\mu}{\eta}\left(\frac{c}{a}\right)
$$

This frequency range, as well as the general time scale for the transient deformation, is associated with the stress relaxation process characterized by the Maxwell relaxation time defined as the ratio

192 between fluid viscosity and elastic modulus of the rock mass. Viscosity of dacites and rhyolitic 193 melts, that are expected to be present in the magmatic systems of the continental crust, is relatively 194 high. The viscosity of rhyolite may be as high as $10^{11} \mathrm{~Pa}$ s for dry melts and decrease to about $10^{6}$ $195 \mathrm{~Pa} \mathrm{~s}$ depending on water content. The Maxwell relaxation time for these melts is of the order of $19610^{-3}-10^{+2} \mathrm{~s}$, overlapping the seismological frequency range. Therefore the (O'Connell and 197 Budiansky, 1977) analysis of fluid-filled cracks could well encompass the seismological 198 observations. However, for typical viscosity range of basaltic melts $10^{0}-10^{2} \mathrm{~Pa} \mathrm{~s}$ and elastic 199 modulus of the order of tens GPa, the Maxwell relaxation time is of the order of $10^{-7}-10^{-9} \mathrm{~s}$, and 200 the effects associated with visco-elastic relaxation are negligibly small after very short time 201 intervals. Accordingly, we may expect significant attenuation only at very high frequency waves. 202 More accurate estimation (eq. 1) predicts that even for a small aspect ratio $c / a \sim 10^{-2}$, the typical 203 frequency range is above $1 \mathrm{KHz}$, which is well above the seismological frequency range. This was 204 already noted by (Mavko, 1980; Mavko et al., 2009), who also discussed squirt flow mechanism. 205 These estimations are compatible with results discussed by Faul et al. (2004) who noted 206 that experimentally observed attenuation in melt-bearing olivine polycrystals reported by Jackson 207 et al. (2004) is not compatible with melt squirt flow through an observed small pipe with aspect 208 ratios around $c / a \sim 10^{-1}$. They also noted that this flow mechanism requires unrealistically high 209 melt viscosity ( $\sim 10^{4} \mathrm{~Pa}$ s). Faul et al. (2004) suggested an alternative stress relaxation mechanism 210 introducing effective viscosity for olivine-olivine grain boundary regions. Adjusting high "grain211 boundary viscosities" ( $\sim 10^{6} \mathrm{~Pa}$ s) allow fitting the observed attenuation; however, the background 212 physical mechanism, responsible for temperature-dependent attenuation, is still not clear. 
In addition, most of the recent works discuss different mechanisms for shear attenuation

214 and neglect bulk attenuation. Vaišnys (1968) and Mavko (1980) discussed the mechanism of bulk

215 attenuation and noted the role of the phase transition between solid and melt phases due to wave-

216 induced pressure oscillations. Li and Weidner (2008) reported results of a complicated laboratory

217 measurement demonstrating effects associated with the presence of phase changes. Their results

218 support the velocity decrease and bulk attenuation observed during loading with a period of 1,000

219 s and the softening observed at low amplitudes and shorter periods. Ricard et al. (2009) and Durand

220 et al. (2012) investigated seismic wave attenuation due solid-solid phase transformation. They

221 considered finite rate of kinetics, but without latent heat generation. Their model successfully

222 predicted seismic mode attenuation associated with phase transition at $410 \mathrm{~km}$ depth (Durand et

223 al., 2012). However, this attenuation mechanism is not very efficient for body waves with typical

224 frequency range $0.1-1 \mathrm{~Hz}$. In the case of the solid-melt phase transition, the characteristic time

225 scale of the of the heat transport generated at the solid-melt interface (latent heat) varies between

226 milliseconds to tens of seconds for melt inclusions of the sizes ranging from tens microns to

227 centimeter scale (Mavko, 1980). Because latent heat is very efficient in releasing energy, it may

228 cause significant attenuation. In this study we develop the analytical solution predicting the impact

229 of the heat generated at the solid-melt phase transition on the bulk elasticity and wave attenuation,

230 considering infinitely fast kinetics.

\section{3. Method}

2333.1 Bulk elasticity, no mass/heat transfer.

234 Zhu et al. (2011) obtained high-resolution 3-D determinations of melt distribution in 235 experimentally produced olivine-basalt aggregates using X-ray synchrotron microtomography. 236 Olivine-basalt aggregates with melt fractions of $0.02,0.05,0.10$, and 0.20 were synthesized from 237 powder mixtures of pulverized natural forsterite and MORB. The spatial resolution of the 238 synchrotron microtomographic images is $\sim 0.7$ microns. Comparison to the conventional 2-D 239 scanning electron microscopy (SEM) images of the same samples demonstrated that the 240 microtomographic method captured realistic melt distribution in 3-D over a large representative 241 volume (Zhu et al., 2011). More information regarding the experimental charges and the image 242 analysis could be found in (Miller et al., 2014). 
Using the reported 3-D melt geometries, Zhu et al. (submitted) recently conducted finite

244 element deformation experiments to obtain the effective bulk and shear moduli of these 245 experimental charges. In the numerical simulations, the numerical elements were dictated by the 246 pixel size of the tomography image with every pixel represented by a cubic brick separated into 247 five tetrahedron elements. The grid avoids any smoothing or averaging of the observed 248 microstructure. The material properties of each pixel (set of five tetrahedron elements) are defined 249 as solid or melt according to the tomographic image. Following (Hammond and Humphreys, 250 2000), we use $K_{S}=124 \mathrm{GPa}, K_{M}=64 \mathrm{GPa}$, and $\mu_{S}=40 \mathrm{GPa}$ (solid Poisson ratio is 0.28). Infinite 251 viscosity (zero fluidity) is defined for the solid phase, while typical viscosity of $10 \mathrm{~Pa}$ s and zero 252 shear modulus are adopted for the melt phase. The viscous strain component act to dampen 253 deformation and facilitates the numerical transient phase that goes from the initial un-deformed 254 equilibrium state to the final static deformed equilibrium one. Boundary conditions for every 255 model run are set according to the simulated loading, i.e., 3-D compaction or uniaxial load. Static 256 stress distribution is simulated using our 3-D code utilizing Fast Lagrangian Algorithm verified in 257 many previous studies.

258 The actual melt fraction, calculated for every sub-volume, depends on the amount of melt 259 generated in the original laboratory sample and also varies between different sub-volumes of the 260 same sample representing the heterogeneity and complex topology of the melt distribution. The 261 lack of any clustering or any preferred location of markers in Fig. 2 corresponding to the size of 262 the numerical grid (100, 200,300, and 400 pixels) confirms that the obtained results are robust and 263 there is no meaningful grid dependency. Colored lines in Fig. 2 show effective elastic moduli 264 predicted by different analytical models discussed in Appendix A. Results of numerical 265 simulations of the effective elastic properties demonstrate that the simple geometrical model of the 266 elastic media with spherical melt inclusions provide the most reliable approximation for the 267 mechanical behavior of the solid-fluid system, in spite of very simplified topology. This topology 268 of the melt distribution in a form of spherical inclusion located in the center of equal cells 269 (schematically shown in Fig. 3) predicts surprisingly well the elastic properties of partially molten 270 rocks, and will be used in the next section to study impact of heat and mass transport across the 271 solid-melt interface. 
A small wave-induced pressure change at a solid-melt interface disturbs the

275 thermodynamic equilibrium and leads to certain motion of the interface. We develop a model for 276 cyclic load with a given amplitude and frequency keeping in mind effects associated with 277 propagation of monochromatic waves. Transient effects related to a final duration of the wave 278 package and temporal variations of the oscillation amplitudes are not considered here. Pressure and deviatoric stress in the solid phase and pressure in the melt, are coupled by stress continuity at

280 the solid-melt interface during external wave-induced load and fluid pressure oscillations. For 281 typical wave amplitude $10^{-5}-10^{-7} \mathrm{~m}$ and wavelength between $0.5-5 \mathrm{~km}$, the deformations of about $28210^{-8}-10^{-10}$ disturbs the thermodynamic equilibrium. Mathematical formulation of this moving 283 boundary or Stefan problem includes heat, mass, and force balance equations. Any pressure change 284 takes the system out of the thermodynamic equilibrium and causes solidification or melting which 285 change the heat balance according to the Clausius-Clapeyron equation. The latent heat (sink or 286 source) is transferred away or towards the interface by conductive-advective mechanism 287 heating/cooling the entire rock mass leading to the energy loss and dissipation of the mechanical 288 energy or seismic wave attenuation. An analytical solution is derived for stress distribution and 289 heat exchange between melt inclusion and solid shell. We neglect the spatial temperature 290 distribution in small melt inclusion. In larger inclusions, effective mixing of the low viscosity fluid 291 probably eliminates any temperature gradients. Therefore we solve for the heat transport only in 292 the solid phase. The analytical solution for the heat balance equation, including latent heat 293 associated with the motion of the solid-melt interface, as well as temperature variations of the melt 294 inclusion, gives the relation between pressure and volumetric strain oscillations. Finally, the 295 derived compressibility of the rock and melt assemblage depends on the characteristics of the 296 external wave-induced forcing. Wave attenuation, or quality factor (Q) is calculated from the time 297 delay between pressure and strain oscillations, or the ratio between real and imaginary bulk 298 moduli.

\section{Results}

Solid-melt phase transition, bulk elasticity and wave attenuation.

$302 \quad$ Numerical model simulating the effective elastic properties and results presented in Fig. 2 303 are obtained assuming mass conservation of melt and solid phases without any mass exchange 304 associated with solid-melt phase transition. However, even small wave-induced pressure change 
at a solid-melt interface disturbs the thermodynamic equilibrium and leads to certain motion of the

306 interface. Pressure changes move the system out of thermodynamic equilibrium, causing 307 solidification or melting which change the heat balance according to the Clausius-Clapeyron 308 equation. The latent heat (sink or source) is transferred away or towards the interface by 309 conductive-advective mechanism, heating or cooling the entire rock mass, leading to energy loss 310 and dissipation of the mechanical energy and to seismic wave attenuation. The presented model is 311 based on the simplified cell geometry representing the partially molten rock as a set of equal elastic 312 cells with spherical melt inclusions (Fig. 3). The simplified cell geometry allows deriving 313 analytical relations for stress distribution and heat exchange between melt inclusion and solid shell 314 considering three different regimes. Each cell representing the solid-melt system is at initial 315 pressure and temperature $\left(P_{0}, T_{0}\right)$, corresponding to the thermodynamic equilibrium according to 316 the phase diagram. The propagating pressure wave, with frequency $\omega$ and long wavelength (well 317 above the cell size) may be considered as time-dependent pressure perturbations at the outer cell 318 boundary, $P_{S}(t)=\delta P_{S} e^{i \omega t}$ (Fig. 3). The elastically deformed solid part of the cell transforms this 319 pressure to the melt inclusion with a certain pressure factor $\psi$, i.e., melt pressure changes 320 proportionally to the pressure wave amplitude, $\delta P_{M} e^{i \omega t}=\psi \cdot \delta P_{S} e^{i \omega t}$, (see Appendix B for 321 complete mathematical derivations). This pressure change violates the thermodynamic 322 equilibrium, which is re-established by the motion of the solid-melt interface. According to the 323 slope of the phase diagram (Clausius-Clapeyron slope, $\alpha$ ) the temperature changes proportionally 324 to the pressure, which relates the latent heat (heat of phase transformation) to the rate of pressure 325 change with temperature (see table 1 for notations):

$$
\frac{d P}{d T}=\frac{L \cdot \rho^{2}}{T \cdot \Delta \rho}=\alpha
$$

327 Neglecting the time required to re-establish the thermodynamic equilibrium, the temperature 328 variations at the solid-melt interface are:

$$
T_{M}(t)-T_{0}=\psi \delta P_{S} e^{i \omega t} / \alpha
$$

330 Heat balance associated with moving solid-melt interface includes latent heat and heating/cooling 331 of the melt inclusion and surrounding solid. Heat variation of small melt inclusion is proportional 332 to its mass and temperature variation, while heat flux in the solid part of the cell is proportional to 333 the temperature gradient at the interface. In Appendix B we provide exact solution for the 
334 temperature distribution in the solid shell with the oscillating boundary condition (3). The obtained 335 solution, in the form of

$$
T(r, t)=\frac{A}{r} e^{i k r} e^{i \omega t}
$$

allows calculating the diffusive heat flux towards the solid shell surrounding the melt inclusion:

339 where

$A_{1}=1+\sqrt{\frac{\omega R^{2}}{2 D}}-\left[\operatorname{Cos}\left(\sqrt{\frac{\omega}{2 D}}(2 S-R)\right)\left(1+\sqrt{\frac{2 \omega S^{2}}{D}}\right)+\operatorname{Sin}\left(\sqrt{\frac{\omega}{2 D}}(2 S-R)\right) \sqrt{\frac{2 \omega S^{2}}{D}}\right] e^{-\sqrt{\frac{\omega}{2 D}}(2 S-R)}$

$A_{2}=\sqrt{\frac{\omega R^{2}}{2 D}}+\left[\operatorname{Sin}\left(\sqrt{\frac{\omega}{2 D}}(2 S-R)\right)\left(1+\sqrt{\frac{2 \omega S^{2}}{D}}\right)-\operatorname{Cos}\left(\sqrt{\frac{\omega}{2 D}}(2 S-R)\right) \sqrt{\frac{2 \omega S^{2}}{D}}\right] e^{-\sqrt{\frac{\omega}{2 D}}(2 S-R)}$

343

344

345

7

Solving the heat balance equation, which also includes latent heat associated with the motion of the solid-melt interface, as well as temperature variations of the melt inclusion, gives the relation between pressure and volumetric strain oscillations. Their ratio $\left(K=K_{R}+i K_{I}=-\delta P_{S} / \delta \varepsilon_{V}\right)$ is the complex bulk modulus:

$$
K=\left\{\frac{1}{K_{e}}+\frac{\beta \gamma \psi}{\alpha L \rho_{S}}\left[\rho_{M} C_{P}+\left(A_{2}-i A_{1}\right) \frac{3 \kappa}{\omega R^{2}}\right]\right\}^{-1}
$$

The ratio $K_{R} / K_{I}$ between the real and imaginary parts of the bulk modulus (7) defines the bulk quality factor, $Q$, of the media (see Appendix B)

$$
Q=\frac{\alpha L \rho_{S} \omega R^{2}+\beta \gamma \psi K_{e} \rho_{M} C_{P} \omega R^{2}+\beta \gamma \psi K_{e} A_{2} 3 \kappa}{K_{e} \beta \gamma \psi A_{1} 3 \kappa}
$$

These derivations demonstrate that moving solid-melt phase boundary due to waveinduced pressure oscillations leads to additional reduction of the bulk modulus, $K_{e}$, estimated from the elastic deformation and provides efficient mechanism for wave attenuation. Most of the material properties in $(6,7,8)$ are well defined with relatively small uncertainty range (e.g., Ricard, 2015). The exception is the product of the Clausius-Clapeyron slope and latent heat values, which according to (2) is expressed as:

$$
\alpha L=\frac{\alpha^{2} T \Delta \rho}{\rho^{2}}
$$

Therefore, we ignore the uncertainty in most of the parameters presented in Table 1, and study the sensitivity of the model predictions to the reasonable variations of the Clausius-Clapeyron slope values $\alpha=3,6,9 \mathrm{MPa} /{ }^{\circ} \mathrm{K}$ (Bina and Helffrich, 1994). Larger slope values, from $\sim 7.5 \mathrm{MPa} /{ }^{\circ} \mathrm{K}$ at 
361 low pressures up to $\sim 30 \mathrm{MPa} /{ }^{\circ} \mathrm{K}$ at $10 \mathrm{GPa}$ were reported by (Hirschmann, 2000) for various 362 compositions of mantle Peridotites.

363 Fig. 4 shows reduction of the bulk modulus as a function of the melt fraction calculated 364 using eq. 7. We define the cell-size, as the typical distance between melt pockets. In brittle 365 rheology, these melt pockets are typically grain-size away from each other, while for ductile rheology they would be further separated. For small cell-size (Fig. 4 a for $S_{0}=0.5 \mathrm{~mm}$ ) the reduction 367 is larger than for relatively large cell-size (Fig. $4 \mathrm{~b}$ for $S_{0}=5.0 \mathrm{~mm}$ ). In both cases smaller Clausius368 Clapeyron slope values lead to more significant effect, since the amplitude of the temperature oscillations at the solid-melt interface (3) is proportional to $1 / \alpha$. The most pronounced change above $80 \%$ reduction occurs at low melt fraction values below $2 \%$ for $\alpha=3$ and $6 \mathrm{MPa} /{ }^{\circ} \mathrm{K}$ (Fig. 4a) and then remains about constant. Larger cell-size (Fig. 4b) causes gradual reduction of the bulk modulus. Values of the quality factor (Q) for $1 \mathrm{~Hz}$-wave frequency, calculated using eq. 8, also strongly depend on these factors (Fig. 5). For small grain size $\left(S_{0}=0.5 \mathrm{~mm}\right)$ the reduction is practically abrupt at very low melt fraction values and then $\mathrm{Q}$ remains practically constant within the values shown by the red polygon in Fig. 5. For larger $S_{0}=5.0 \mathrm{~mm}$, the Q decrease is steeper for small $\alpha$-values and approach about constant value at melt fraction values above $\sim 5 \%$. Since the presented model ignores wave attenuation in the solid phase, the Q-values go to infinity for zero melt fraction value $(\beta=0)$.

Wave attenuation predicted by the model, is strongly frequency-dependent (Fig. 6). Less attenuation or higher Q-values are obtained at very low and high frequency values. If the oscillation period is very large, the whole cell volume is heated to the equilibrium temperature and the delay associated with heat transfer is small. Similarly, heat transfer can be neglected at very small period values. The highest attenuation occurs when the period of oscillation is close to the heat transfer time scale. In this condition, any heating that occurs due to Solid-melt phase transition during the 385 oscillation is affecting the entire cell and therefore causing high attenuation. The time needed to transfer heat over the cell size or the characteristic time scale of conductive heat transfer over the cell size is defined as $S_{0}^{2} D$. Therefore, the largest attenuation occurs when $f \cdot S_{0}^{2} / D \sim 1$. For small 388 cell-size (Fog. 6a) maximum attenuation is expected at frequency range, $f$, between 1 and $10 \mathrm{~Hz}$. 389 Q-values are very low and weakly depend on the melt fraction. One order of magnitude increase 390 in the cell-size causes two orders of magnitude $\left(S_{0}^{2}\right)$ frequency change $(0.01-0.1 \mathrm{~Hz})$ for maximum 
391 attenuation (Fig. 6b). In both cases, the increase in Q-values at low frequencies only weakly

392 depends on the melt fraction, while it is significantly more sensitive at high frequencies.

\section{Discussion}

Understanding how magma or molten rocks are stored at depth is one of the major challenges in volcanology, igneous geology, mantle dynamics, and plate tectonics. Many of the ongoing geodynamic key processes and related natural hazards require information on the distribution of partial melt storage system and reservoirs in the Earth's crust and upper mantle. Seismological methods are often used to show areas of significant reduction in seismic wave velocities and enhanced wave attenuation, and are interpreted as revealing pockets of partially molten rocks. Interpretation of the seismological observations requires understanding of the effects of the properties of the partially molten rocks on the melt fraction and on the topology of melt inclusions.

Previous studies show that viscous dissipation due to flow or squirt of the melt with realistic viscosity range is small and expected attenuation is well below the typical values for the partially molten rocks. The developed analytical model shows that phase transition is an efficient mechanism for strong attenuation and for the reduction of wave velocity. The model adopts cell geometry for spherical melt inclusions in partially melted rocks (Fig. 3). Previous results discussed by Zhu et al. (submitted) and shown in Fig. 2 demonstrate that in spite of a complex melt topology, this simple geometrical model provides surprisingly good approximation for the effective rock elasticity. This important result allows using analytical solutions, assuming spherical inclusions, for estimating effective elastic properties and modeling wave attenuation.

414 solid-melt phase transition out of the consideration is the Hashin-Shtrikman-Walpole model.

415 Their model predicts relatively minor reduction in both pressure and shear wave velocities with 416 melt fraction (Fig. 7). However, even for relatively large cell-size $\left(S_{0}=5 \mathrm{~mm}\right)$ and intermediate 417 Clausius-Clapeyron slope value, $\alpha=5 \mathrm{MPa} /{ }^{\circ} \mathrm{K}$, the reduction in the bulk modulus associated with 418 the phase transition is dominant (Fig. 7). The analytical solution considers only spherical symmetry 419 and volumetric deformation, and formally cannot relate phase transition to shearing, which in 420 perfect material is decoupled from volumetric deformation. However, original studies by Reynolds 421 (1885) and Skempton (1954), have shown that shear stress is strongly coupled with pressure, and 
422 therefore the formal decoupling is in doubt. Taking into account the relation between S-wave 423 induced shearing and pressure, we speculate here that propagating S-waves will also lead to similar 424 phase boundary motion, i.e., velocity reduction and attenuation. Dashed red line in Fig. 7 shows 425 the inferred shear modulus reduction using the same factor as for the P-waves. More accurate 426 relations for the S-waves will be examined in future study.

427 In summary, the analyzed mechanism of reduction in mechanical properties associated 428 with the phase transition predicts that the presence of significant amount of melt in the rocks would 429 result in a strong decrease in seismic wave velocities associated with a strong increase of their 430 attenuation. Preliminary consideration also indicates that the velocity decrease should be more 431 enhanced for $\mathrm{S}$ wave (Fig. 7), resulting in the increase of the $\mathrm{Vp} / \mathrm{Vs}$ ratio. This implies that 432 simultaneous measurement of these properties could help to better constrain the melt content in 433 studied geological objects such as, for example, volcanic systems. A key parameter for 434 interpretation of such results is the average cell-size $\mathrm{S}_{0}$, that remains poorly known. Results shown 435 in Fig. 6 indicate that this parameter cannot be too small $(<1 \mathrm{~mm})$ because in this case the waves 436 at frequencies between 1 and $10 \mathrm{~Hz}$ (i.e. typical range of observation for volcanic earthquakes) 437 would be completely dissipated $(\mathrm{Q}<5)$. Considering the millimeter or centimeter scale of the melt 438 distribution spatial heterogeneity would result in more appropriate predictions with Q varying 439 between 10 and several hundreds at $1 \mathrm{~Hz}$. Moreover, with such values of $\mathrm{S}_{0}$, the model predicts an 440 approximately power-law increase of Q at high frequencies, i.e., the behavior reported from field 441 observations and laboratory experiments (Lekić et al., 2009). Overall, the predicted values are 442 approximately in agreement with large scale seismological observations showing that seismic 443 waves are mostly attenuated within the shallow parts of the Earth's crust and mantle, and 444 associated with possible presence of melt, such as in mid-oceanic ridges and island arcs or beneath 445 large volcanic systems. The model is also in agreement with observed significant correlation 446 between the regional-scale tectonics and the geographical distributions of uppermost-mantle 447 velocities and attenuation for $\mathrm{S}$ and $\mathrm{P}$ waves. So far, average $\mathrm{Q}$ being as low as $\sim 60$ in the upper 448 mantle low velocity zone, where significant amount of melt may be expected (e.g., Thybo, 2006). 449 The presented model considers latent heat generation at the solid-melt phase transition and 450 heat transport near the interface. Adopting infinitely fast kinetics, the model predicts the realistic 451 body wave attenuation with the frequency range 0.1-1 Hz. The alternative approach considering 452 solid-solid transition with finite phase (Durand et al., 2012; Ricard et al., 2009), predicts maximum 
453 attenuation at significantly lower frequency range typical for free oscillations. The real case might 454 be somewhat in between and the complete model should consider both type of the phase 455 transitions.

\section{Conclusion}

In spite of the complex structure of partially molten rocks, effective elastic moduli can be 459 approximated assuming spherical melt inclusions geometry, which implies that the exact topology 460 of the melt even at high melt fraction values is not crucial. Viscous flow mechanisms for basaltic 461 melts can cause attenuation only at very high frequency waves. Explaining observed wave 462 attenuation in partially molten peridotite rocks using viscous flow requires adjusting unrealistically 463 high viscosities.

464 We present a new mechanism for wave velocity reduction and attenuation associated with 465 moving solid-melt interface (Stefan problem), and latent heat generation due to wave-induced 466 pressure oscillations around thermodynamic equilibrium. The reduction in mechanical properties 467 (seismic velocities) associated with the phase transition is shown to be significant. The highest 468 attenuation occurs when the period of oscillation is close to the heat transfer time scale. In this 469 condition, any heating that occurs due to Solid-melt phase transition during the oscillation is 470 affecting the entire cell and therefore causes high attenuation.

\section{Acknowledgements}

473 We thank Claude Jaupart and Navot Murag for discussions. The paper benefited from useful 474 comments by two anonymous referees and the editor, Hans Thybo. This study was supported by 475 the Russian Ministry of Education and Science (Grant 14.W03.31.0033) and by the European 476 Research Council under the European Union Horizon 2020 research and innovation program 477 (Grant Agreement 787399-SEISMAZE). 
479 Table 1. Values of the model constants.

\begin{tabular}{|c|c|c|}
\hline Notation & Parameter & Value/units \\
\hline$K_{\mathrm{S}}$ & Solid bulk modulus & $124 \mathrm{GPa}$ \\
\hline$\mu_{\mathrm{S}}$ & Solid shear modulus & $64 \mathrm{GPa}$ \\
\hline$v_{\mathrm{S}}$ & Solid Poisson ratio & 0.28 \\
\hline$K_{\mathrm{M}}$ & Melt bulk modulus & $40 \mathrm{GPa}$ \\
\hline$K_{\mathrm{e}}$ & Effective bulk modulus & $\mathrm{GPa}$ \\
\hline$\mu_{\mathrm{e}}$ & Effective shear modulus & $\mathrm{GPa}$ \\
\hline$\beta$ & Melt fraction & $0-20 \%$ \\
\hline$\alpha$ & Clausius-Clapeyron slope & $1-10 \mathrm{MPa} /{ }^{\circ} \mathrm{K}$ \\
\hline$\kappa$ & Heat conductivity & $3.5 \mathrm{~J} / \mathrm{s} \mathrm{m}{ }^{\mathrm{o}} \mathrm{K}$ \\
\hline$C_{\mathrm{p}}$ & Heat capacity & $1 \mathrm{~kJ} / \mathrm{kg}^{\mathrm{o}} \mathrm{K}$ \\
\hline$L$ & Specific latent heat & $10^{2}-10^{3} \mathrm{~kJ} / \mathrm{kg}$ \\
\hline$\rho_{\mathrm{S}}$ & Solid density & $3,500 \mathrm{~kg} / \mathrm{m}^{3}$ \\
\hline$\rho_{\mathrm{M}}$ & Melt density & $3,000 \mathrm{~kg} / \mathrm{m}^{3}$ \\
\hline$D=\frac{\kappa}{\rho_{S} C_{P}}$ & Thermal diffusivity & $110^{-6} \mathrm{~m}^{2} / \mathrm{s}$ \\
\hline$S_{0}$ & Cell radius & $0.5-510^{-3} \mathrm{~m}$ \\
\hline$R=S_{0} \sqrt[3]{\beta}$ & Inclusion radius & M \\
\hline$\gamma$ & Volumetric strain factor & 0.25 \\
\hline$\psi$ & Pressure factor & 0.54 \\
\hline
\end{tabular}




\section{References}

Allen, R.M., Nolet, G., Morgan, .W.J., Vogfjörd, K., Bergsson, B.H., Erlendsson, P., Foulger, G.R., Jakobsdóttir, S., Julian, B.R., Pritchard, M., 2002. Imaging the mantle beneath Iceland using integrated seismological techniques. J. Geophys. Res. Solid Earth 107, ESE-3.

Asimow, P.D., Langmuir, C.H., 2003. The importance of water to oceanic mantle melting regimes. Nature 421, 815-820.

Baba, K., Chave, A.D., Evans, R.L., Hirth, G., Mackie, R., 2006. Mantle dynamics beneath the East Pacific Rise at $17 \mathrm{~S}$ : Insights from the Mantle Electromagnetic and Tomography (MELT) experiment. J. Geophys. Res. Solid Earth 111.

Bina, C.R., Helffrich, G., 1994. Phase transition Clapeyron slopes and transition zone seismic discontinuity topography. J. Geophys. Res. Solid Earth 99, 15853-15860.

Bryan, S.E., Peate, I.U., Peate, D.W., Self, S., Jerram, D.A., Mawby, M.R., Marsh, J.S.G., Miller, J.A., 2010. The largest volcanic eruptions on Earth. Earth-Science Rev. 102, $207-$ 229.

Campbell, I., 2005. Large Igneous Provinces and the Mantle Plume Hypothesis. Elements 1, 265-269.

Chantel, J., Manthilake, G., Andrault, D., Novella, D., Yu, T., Wang, Y., 2016. Experimental evidence supports mantle partial melting in the asthenosphere. Sci. Adv. 2, e1600246.

Chen, J., Gaillard, F., Villaros, A., Yang, X., Laumonier, M., Jolivet, L., Unsworth, M., Hashim, L., Scaillet, B., Richard, G., 2018. Melting conditions in the modern Tibetan crust since the Miocene. Nat. Commun. 9, 1-13.

Chouet, B., 1996. Long-period volcano seismicity: its source and use in eruption forecasting. Nature 380, 309-316.

Conder, J.A., Forsyth, D.W., Parmentier, E.M., 2002. Asthenospheric flow and asymmetry of the East Pacific Rise, MELT area. J. Geophys. Res. Solid Earth 107, ETG-8.

Debayle, E., Bodin, T., Durand, S., Ricard, Y., 2020. Seismic evidence for partial melt below tectonic plates. Nature 586, 555-559.

Di Toro, G., Hirose, T., Nielsen, S., Pennacchioni, G., Shimamoto, T., 2006. Natural and experimental evidence of melt lubrication of faults during earthquakes. Science (80-. ). 311, 647-649.

Durand, S., Chambat, F., Matas, J., Ricard, Y., 2012. Constraining the kinetics of mantle phase changes with seismic data. Geophys. J. Int. 189, 1557-1564.

Ekström, G., Dziewonski, A.M., 1998. The unique anisotropy of the Pacific upper mantle. Nature 394, 168-172.

Faul, U., Jackson, I., 2015. Transient Creep and Strain Energy Dissipation: An Experimental Perspective. Annu. Rev. Earth Planet. Sci. https://doi.org/10.1146/annurev-earth-060313054732

Faul, U.H., Fitz, G.J.D., Jackson, I., 2004. Shear wave attenuation and dispersion in meltbearing olivine polycrystals: 2 . Microstructural interpretation and seismological implications. J. Geophys. Res. Solid Earth 109.

Fontaine, F.R., Ildefonse, B., Bagdassarov, N.S., 2005. Temperature dependence of shear wave attenuation in partially molten gabbronorite at seismic frequencies. Geophys. J. Int. 163, 1025-1038. https://doi.org/10.1111/j.1365-246X.2005.02767.x

Gerya, T., Meilick, F.I., 2011. Geodynamic regimes of subduction under an active margin: effects of rheological weakening by fluids and melts. J. Metamorph. Geol. 29, 7-31.

Hammond, W.C., Humphreys, E.D., 2000. Upper mantle seismic wave velocity: Effects of 
realistic partial melt geometries. J. Geophys. Res. Solid Earth 105, 10975-10986.

Hill, G.J., Caldwell, T.G., Heise, W., Chertkoff, D.G., Bibby, H.M., Burgess, M.K., Cull, J.P., Cas, R.A.F., 2009. Distribution of melt beneath Mount St Helens and Mount Adams inferred from magnetotelluric data. Nat. Geosci. 2, 785-789.

Hirschmann, M.M., 2000. Mantle solidus: Experimental constraints and the effects of peridotite composition. Geochemistry, Geophys. Geosystems 1.

Jackson, I., Faul, U.H., Fitz, G.J.D., Tan, B.H., 2004. Shear wave attenuation and dispersion in melt- bearing olivine polycrystals: 1 . Specimen fabrication and mechanical testing. J. Geophys. Res. Solid Earth 109.

Jackson, M.D., Blundy, J., Sparks, R.S.J., 2018. Chemical differentiation, cold storage and remobilization of magma in the Earth's crust. Nature 564, 405-409.

Jaxybulatov, K., Shapiro, N.M., Koulakov, I., Mordret, A., Landès, M., Sens-Schönfelder, C., 2014. A large magmatic sill complex beneath the Toba caldera. Science (80-. ). 346, 617619.

Karato, S.-I., Spetzler, H.A., 1990. Defect microdynamics in minerals and solid- state mechanisms of seismic wave attenuation and velocity dispersion in the mantle. Rev. Geophys. 28, 399-421.

Koulakov, I., Shapiro, N.M., Sens- Schönfelder, C., Luehr, B.G., Gordeev, E.I., Jakovlev, A., Abkadyrov, I., Chebrov, D.V., Bushenkova, N., Droznina, S.Y., 2020. Mantle and crustal sources of magmatic activity of Klyuchevskoy and surrounding volcanoes in Kamchatka inferred from earthquake tomography. J. Geophys. Res. Solid Earth 125, e2020JB020097.

Lekić, V., Matas, J., Panning, M., Romanowicz, B., 2009. Measurement and implications of frequency dependence of attenuation. Earth Planet. Sci. Lett. 282, 285-293.

Li, L., Weidner, D.J., 2008. Effect of phase transitions on compressional-wave velocities in the Earth's mantle. Nature 454, 984-986. https://doi.org/10.1038/nature07230

Mavko, G., 1980. Velocity and attenuation in partially molten rocks. J. Geophys. Res. Solid Earth 85, 5173-5189.

Mavko, G., Mukerji, T., Dvorkin, J., 2009. The rock physics handbook Second Edition. Cambridge University Press.

Miller, K.J., Zhu, W., Montési, L., Gaetani, G.A., 2014. Experimental quantification of permeability of partially molten mantle rock. Earth Planet. Sci. Lett. 388, 273-282.

Morris, S.J.S., Jackson, I., 2009. Diffusionally assisted grain-boundary sliding and viscoelasticity of polycrystals. J. Mech. Phys. Solids. https://doi.org/10.1016/j.jmps.2008.12.006

Niu, Y., 1997. Mantle Melting and Melt Extraction Processes beneath Ocean Ridges: Evidence from Abyssal Peridotites. J. Petrol. 38, 1047-1074. https://doi.org/10.1093/petroj/38.8.1047

O’Connell, R.J., Budiansky, B., 1977. Viscoelastic properties of fluid- saturated cracked solids. J. Geophys. Res. 82, 5719-5735.

Pinel, V., Jaupart, C., Albino, F., 2010. On the relationship between cycles of eruptive activity and growth of a volcanic edifice. J. Volcanol. Geotherm. Res. 194, 150-164.

Prudencio, J., Manga, M., 2020. 3-D seismic attenuation structure of Long Valley caldera: looking for melt bodies in the shallow crust. Geophys. J. Int. 220, 1677-1686.

Reuss, A., 1929. Berechnung der fließgrenze von mischkristallen auf grund der plastizitätsbedingung für einkristalle. ZAMM- Journal Appl. Math. Mech. für Angew. Math. und Mech. 9, 49-58.

Reynolds, O., 1885. LVII. On the dilatancy of media composed of rigid particles in contact. With experimental illustrations. London, Edinburgh, Dublin Philos. Mag. J. Sci. 20, 469-481. 
Ricard, Y., 2015. 7.02 - Physics of Mantle Convection, in: Schubert, G. (Ed.), . Elsevier, Oxford, pp. 23-71. https://doi.org/https://doi.org/10.1016/B978-0-444-53802-4.00127-5

Ricard, Y., Matas, J., Chambat, F., 2009. Seismic attenuation in a phase change coexistence loop. Phys. Earth Planet. Inter. 176, 124-131. https://doi.org/https://doi.org/10.1016/j.pepi.2009.04.007

Rychert, C.A., Laske, G., Harmon, N., Shearer, P.M., 2013. Seismic imaging of melt in a displaced Hawaiian plume. Nat. Geosci. 6, 657-660.

Shapiro, N.M., Droznin, D.V., Droznina, S.Y., Senyukov, S.L., Gusev, A.A., Gordeev, E.I., 2017. Deep and shallow long-period volcanic seismicity linked by fluid-pressure transfer. Nat. Geosci. 10, 442-445.

Skempton, A.W., 1954. The pore-pressure coefficients A and B. Geotechnique 4, 143-147.

Sobolev, S.V., Sobolev, A.V., Kuzmin, D.V., Krivolutskaya, N.A., Petrunin, A.G., Arndt, N.T., Radko, V.A., Vasiliev, Y.R., 2011. Linking mantle plumes, large igneous provinces and environmental catastrophes. Nature 477, 312-316.

Thybo, H., 2006. The heterogeneous upper mantle low velocity zone. Tectonophysics 416, $53-$ 79. https://doi.org/https://doi.org/10.1016/j.tecto.2005.11.021

Vaišnys, J.R., 1968. Propagation of acoustic waves through a system undergoing phase transformations. J. Geophys. Res. 73, 7675-7683.

van Hunen, J., Zhong, S., Shapiro, N.M., Ritzwoller, M.H., 2005. New evidence for dislocation creep from 3-D geodynamic modeling of the Pacific upper mantle structure. Earth Planet. Sci. Lett. 238, 146-155.

Voigt, W., 1890. Bestimmung der Elasticitätsconstanten des brasilianischen Turmalines. Ann. Phys. 277, 712-724. https://doi.org/10.1002/andp.18902771205

Watanabe, T., Kurita, K., 1993. The relationship between electrical conductivity and melt fraction in a partially molten simple system: Archie's law behavior. Phys. earth Planet. Inter. 78, 9-17.

Yamauchi, H., Takei, Y., 2016. Polycrystal anelasticity at near-solidus temperatures. J. Geophys. Res. Solid Earth 121, 7790-7820. https://doi.org/10.1002/2016JB013316

Zhu, W., Gaetani, G.A., Fusseis, F., Montési, L.G.J., De Carlo, F., 2011. Microtomography of partially molten rocks: three-dimensional melt distribution in mantle peridotite. Science (80-. ). 332, 88-91. https://doi.org/10.1126/science.1202221 
608

609

610

611

612

613

614

615

616

617

618

619

620

621

622

623

624

625

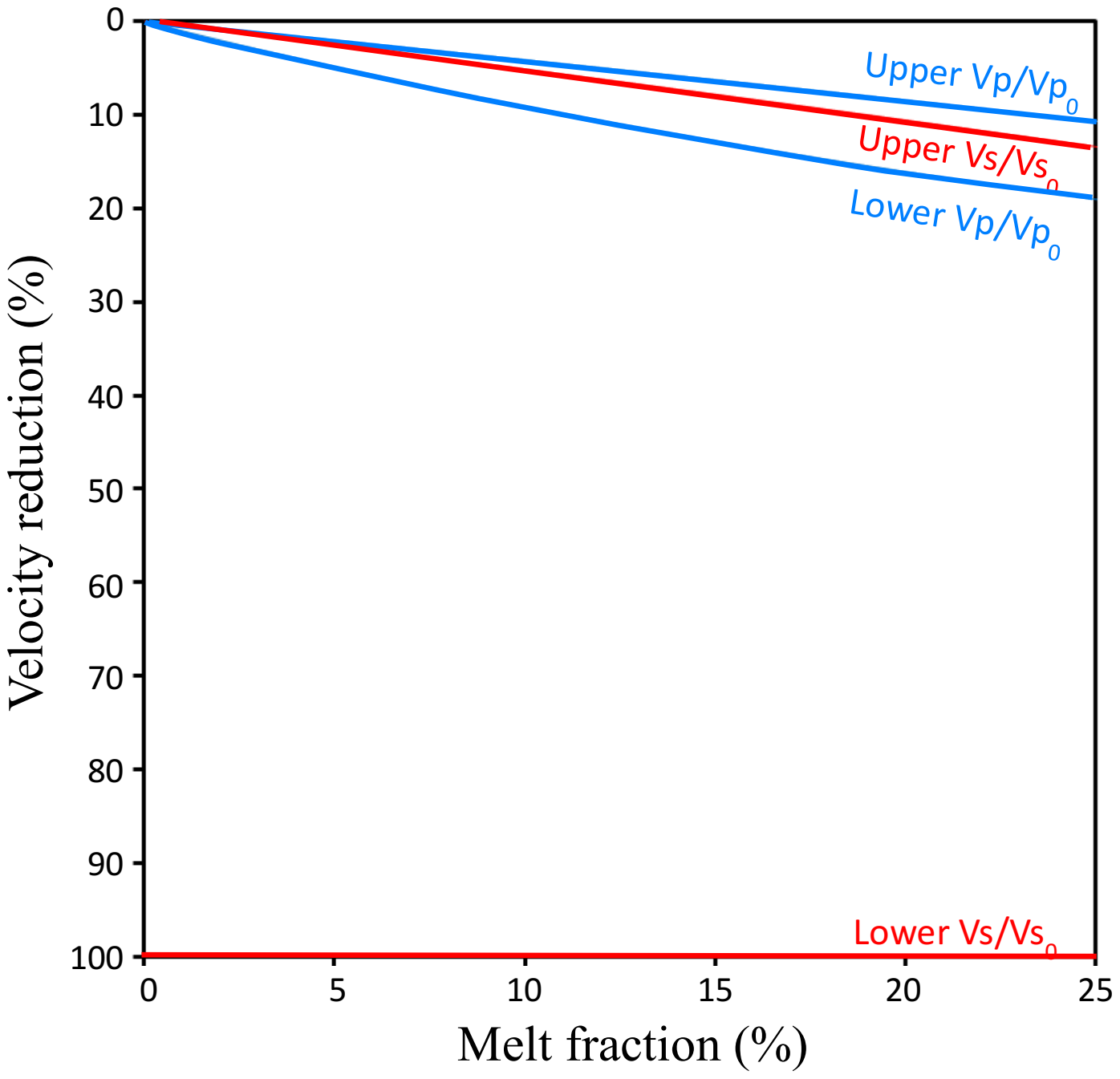

626

Figure 1: Upper and lower bounds for velocity reduction according to the iso-strain (Upper) and iso-stress (Lower) models, for both, Vp (blue) and Vs (red) seismic velocities.

627

628

629

630

631

632

633

634

635

636 


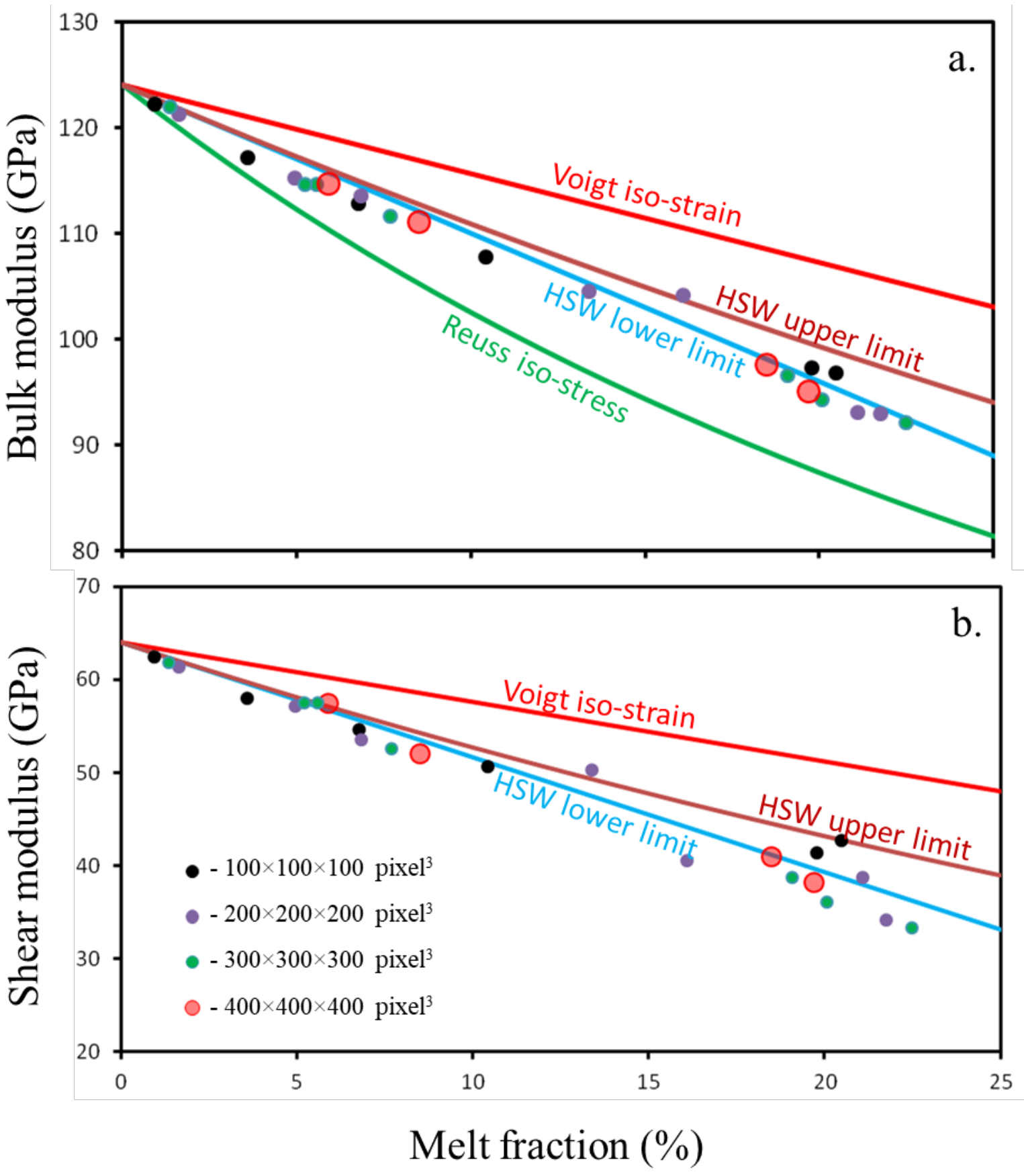

Figure 2: Elastic moduli, bulk (a) and shear (b) for partially molten rock. HSW -

643 Hashin-Shtrikman-Walpole model. 


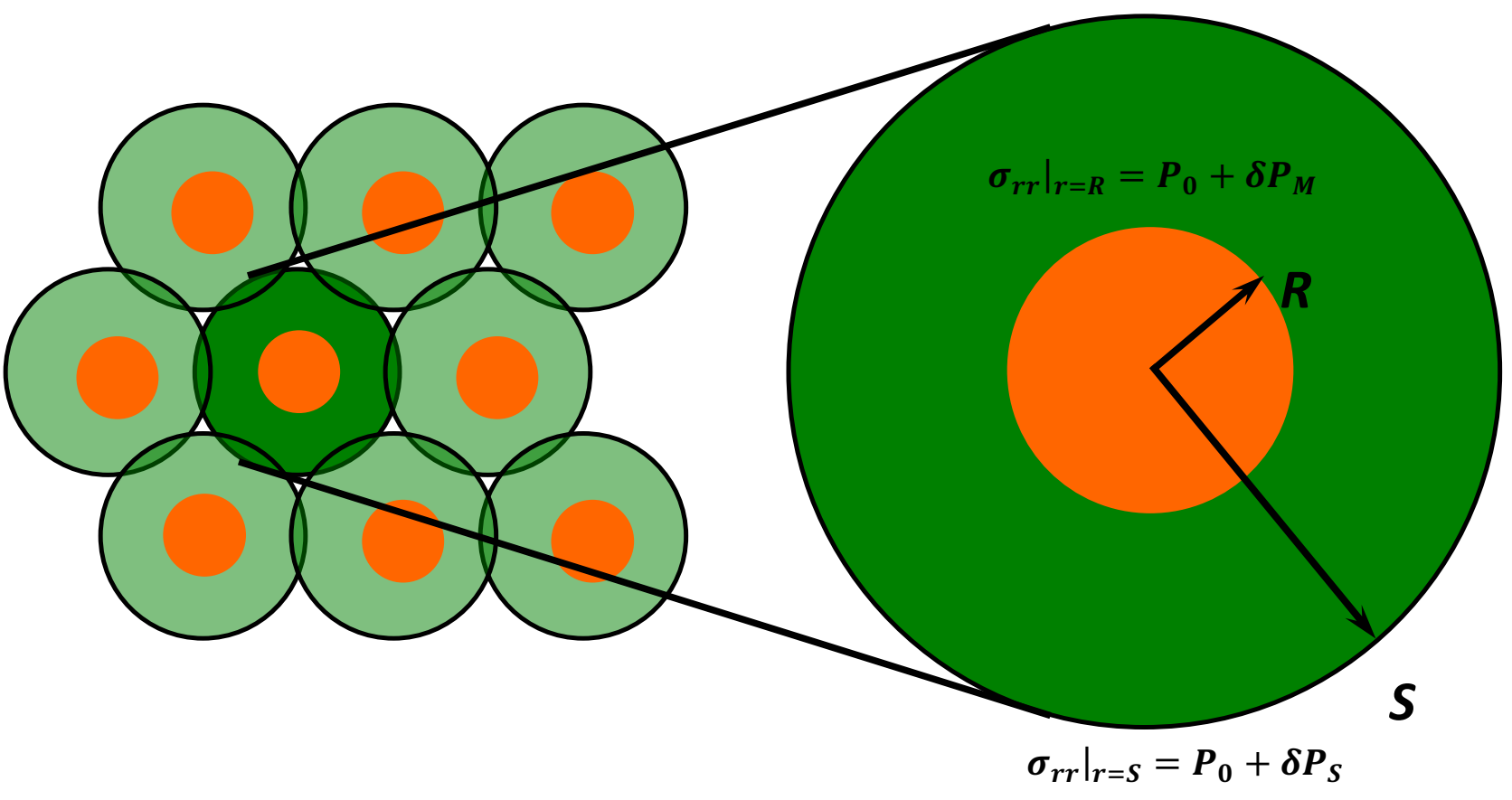

Figure 3: The cell model for spherical melt inclusions in partially melted rocks (see text for further explanation). $R$ and $S$ are the radii of the inclusion and cell, respectively, $\sigma_{r r}$

662 is the radial component of the stress in the cell, $P_{0}$ is the equilibrium external pressure,

663 under which the melt inclusion co-exists with the surrounding solid shell, and $\delta P_{M}$ and $\delta P_{S}$

664 are the pressure oscillations at the inner and outer solid cell boundaries. 


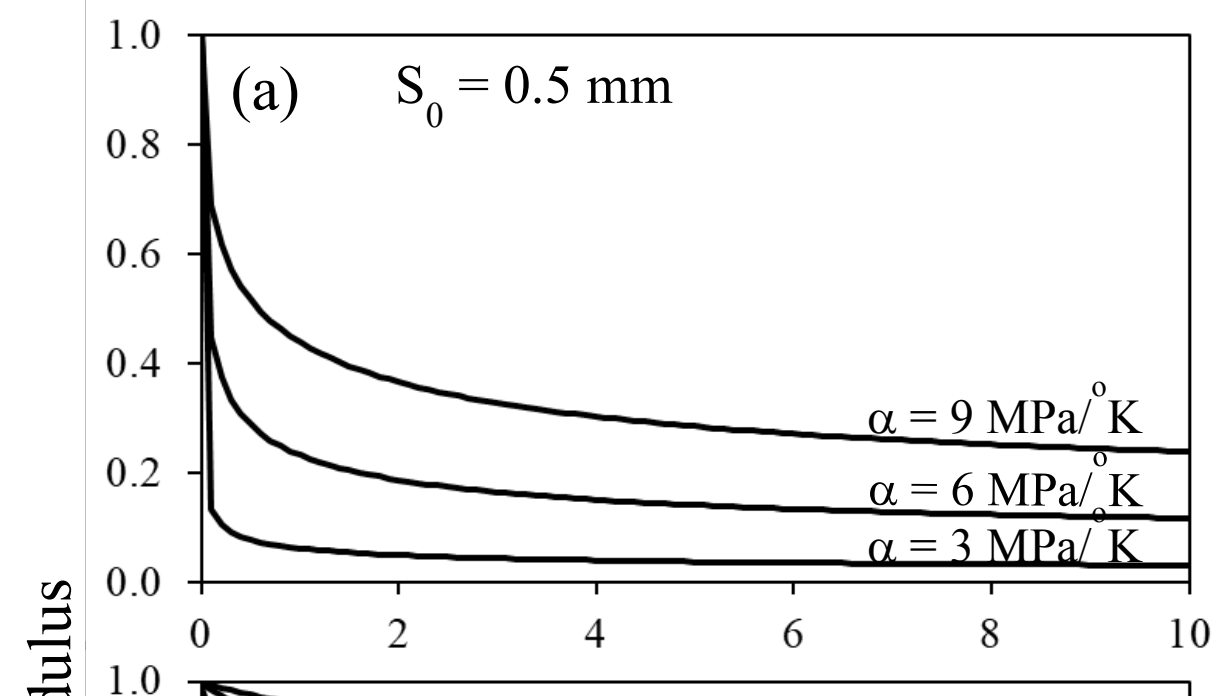

.

ह
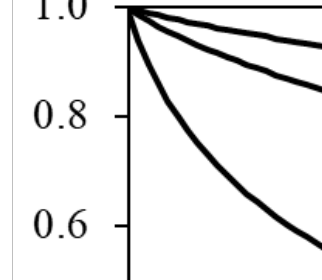

鹿

0.4

:

0.2

(b) $\mathrm{S}_{0}=5.0 \mathrm{~mm}$
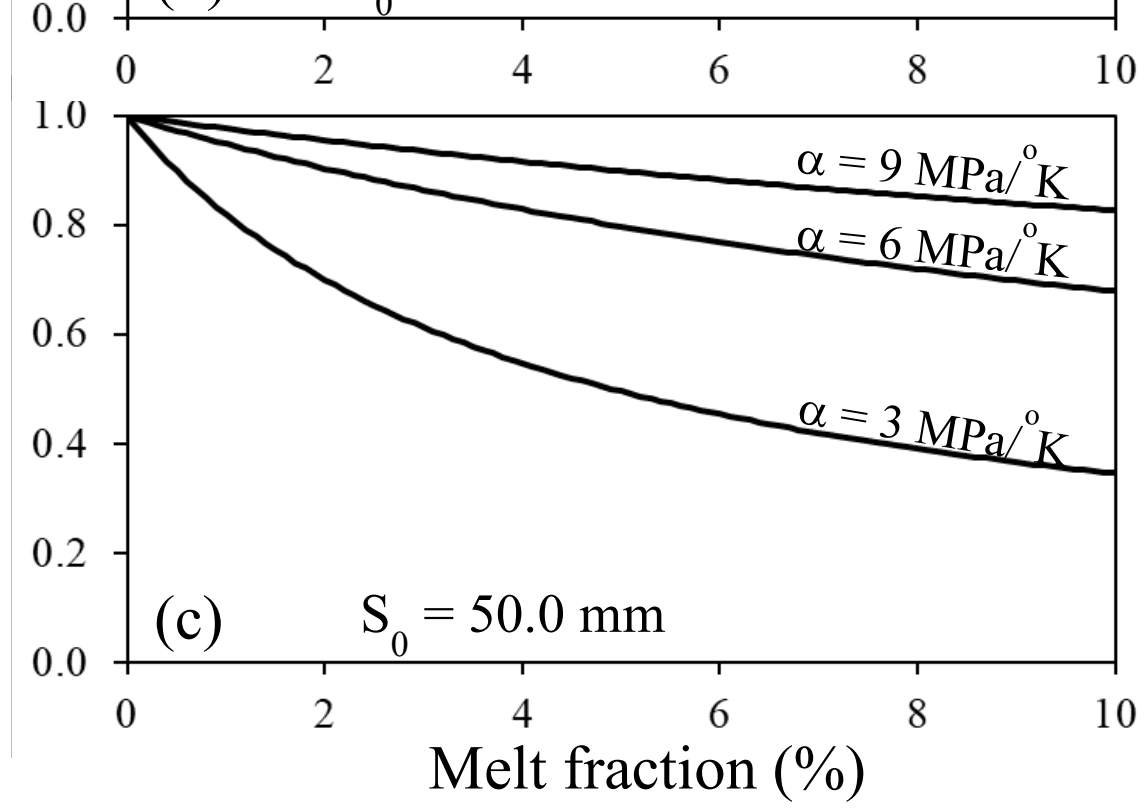

700

Figure 4: Reduction of the bulk modulus versus melt fraction for different Clausius-

703 Clapeyron slope values $\mathrm{a}=3,6$, and $9 \mathrm{MPa} /{ }^{\circ} \mathrm{K} ; \mathrm{S}_{0}=0.5 \mathrm{~mm}$ (a), $5.0 \mathrm{~mm}$ (b), and $50.0 \mathrm{~mm}$ 704 (c), and $1 \mathrm{~Hz}$ frequency. 


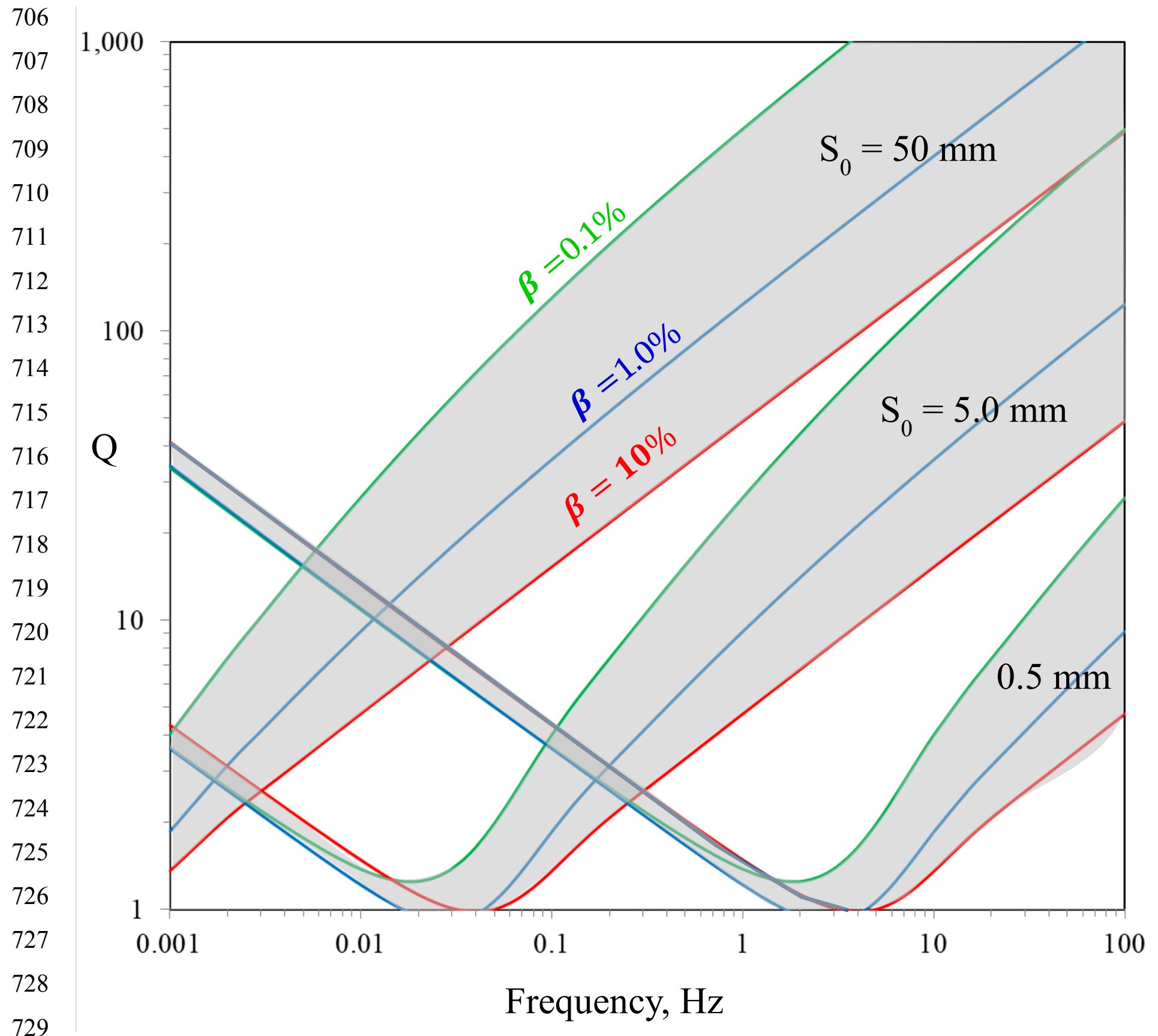

730

731

732 Figure 6: $Q$ versus frequency for different melt fraction values $\mathrm{b}=0.1 \%, 1.0 \%$, and $73310 \%$ and Clausius-Clapeyron slope value $\mathrm{a}=5 \mathrm{MPa} /{ }^{\circ} \mathrm{K}$. Shaded polygons show Q-values for $734 \mathrm{~S}_{0}=0.5 \mathrm{~mm}, 5.0 \mathrm{~mm}$, and $50.0 \mathrm{~mm}$.

735 


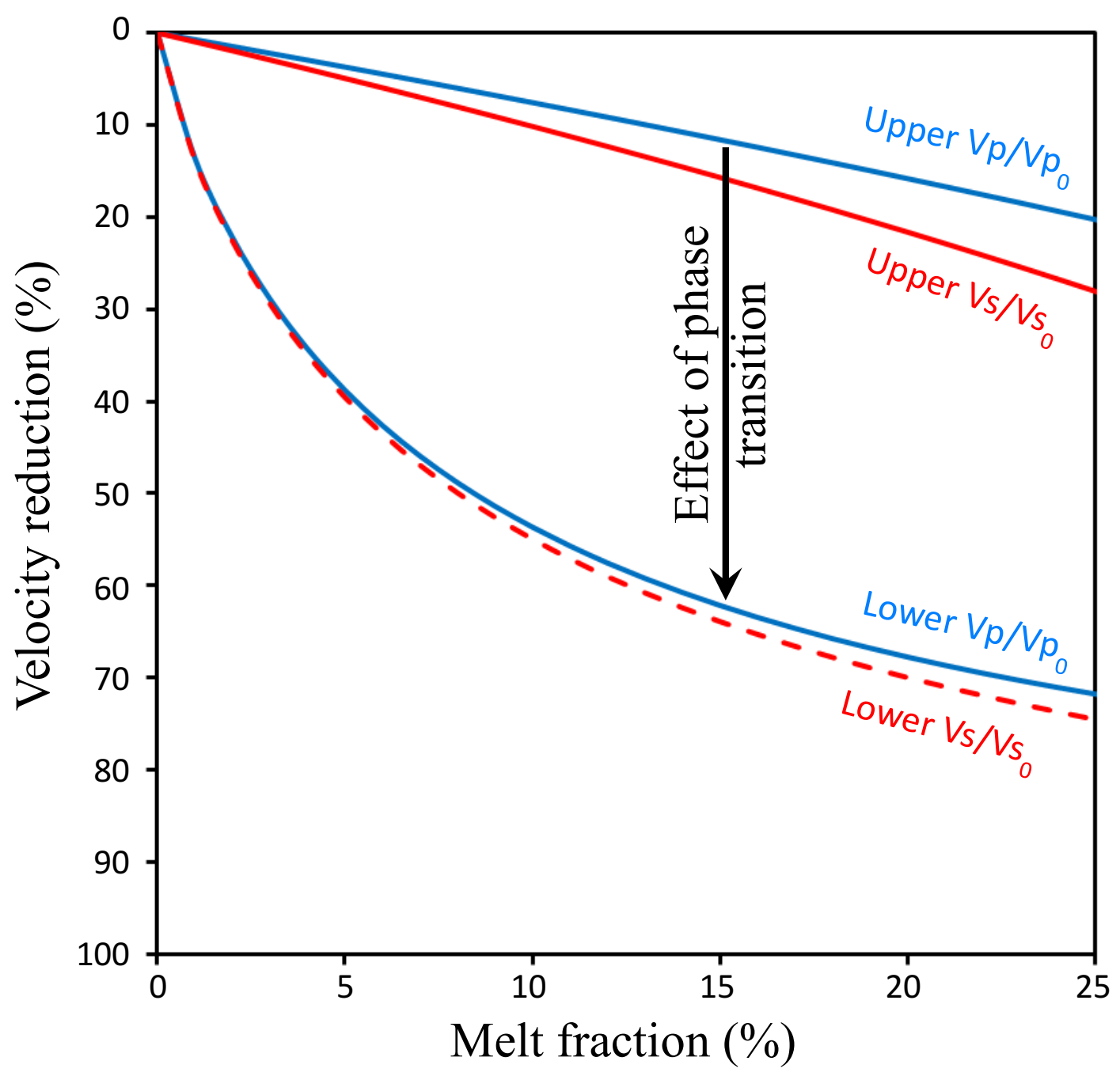

758 corrected after the phase transition effect for $\mathrm{S}_{0}=5.0 \mathrm{~mm}, \mathrm{a}=5 \mathrm{MPa} /{ }^{\circ} \mathrm{K}$, and $1 \mathrm{~Hz}$

759 frequency. 